\title{
Measurement of diastolic closure rate of normal mitral valve
}

\author{
J. Christine Rodger and David J. Sumner \\ From the Medical Division, Stobhill General Hospital; and the Department of Clinical Physics and Bio- \\ engineering, West of Scotland Health Boards, Glasgow
}

Published values for the diastolic closure rate of the normal mitral valve vary and reflect differences in methods of recording and measurement.

From strip chart records it was concluded that the form of the recorded mitral diastolic closure slope can vary, that reproducible measurements of the closure rate can be made from echograms in which diastolic closure approximates closely to a monophasic form, that the amplitude of these echograms is maximal, and that their closure movements remain essentially monophasic at chart speeds up to $100 \mathrm{~mm} / \mathrm{s}$.

Measuring only complexes with essentially monophasic closure movements, the within and between-subject variation of the normal mitral diastolic closure rate was investigated. The ranges obtained from multiple measurements in a single subject and from a group of 45 normal subjects were comparable but the distribution of the results differed. It was concluded that there was a real between-subject variation in the normal mitral diastolic closure rate and that the diastolic closure rate in a single subject should be determined by measurement of a series of complexes.

The accuracy of measurement of the diastolic closure rate of the normal mitral valve has been improved by using strip chart records and by measuring only echograms in which diastolic closure approximates closely to a monophasic form.

Although echocardiography is being increasingly accepted as a valid method of cardiac investigation, instrumentation and recording techniques are not yet standardized (Joyner, I972). No standard methods of measurement from recorded echograms have been described and the within-subject variation of such measurements has not been assessed.

Edler (196I) was the first to measure the diastolic closure rate of the mitral valve from the anterior cusp echogram in normal subjects. Published values for the diastolic closure rate of the normal mitral valve vary (Table). This variation, which undoubtedly reflects differences in methods of recording, may also reflect differences in methods of measurement.

There is general agreement on the diastolic closure rate of the rheumatic mitral valve: the information obtained from this measurement is clinically useful and has been well substantiated (Effert et al., r964; Segal, Likoff, and Kingsley, 1966; Edler, 1967; Winters et al., 1967). In nonrheumatic mitral regurgitation (Segal, Likoff, and Received 30 October 1974 .
Kingsley, 1967; Sweatman et al., 1972; Tallury, DePasquale, and Burch, 1972 ; Millward, McLaurin, and Craige, 1973) and in congestive cardiomyopathy (Ziady et al., 1973; Millward et al., I973; Layton et al., 1973), the published mitral valve diastolic closure rates are quite widely discrepant. Until all echocardiographic records and the methods of measurement from them are comparable, studies of closure rates by different groups of workers will continue to produce confusing results.

The mitral valve diastolic closure rate, considered in conjunction with other echocardiographic and haemodynamic measurements, may provide an index of left ventricular filling (Layton et al., 1973). Before this suggestion can be validated, more precise and reproducible measurement of the diastolic closure rate is necessary.

In this paper we describe how the form of the diastolic closure slope recorded from a normal mitral valve can vary. We indicate to what extent this variation alters the diastolic closure rate measured from the slope and we suggest a standard method of measurement. 
TABLE Published values for diastolic closure rate of normal mitral valve

\begin{tabular}{|c|c|c|c|}
\hline & $\begin{array}{l}\text { No. of } \\
\text { subjects } \\
\text { studied }\end{array}$ & $\begin{array}{l}\text { Diastolic closure } \\
\text { rate }- \text { range } \\
(\mathrm{mm} / \mathrm{s})\end{array}$ & $\begin{array}{l}\text { Diastolic closure } \\
\text { rate - mean } \\
(\mathrm{mm} / \mathrm{s})\end{array}$ \\
\hline $\begin{array}{l}\text { Edler (r96r) } \\
\text { Joyner, Reid, and Bond (1963) }\end{array}$ & $\begin{array}{l}77 \\
25\end{array}$ & $\begin{array}{l}80- \\
85-160\end{array}$ & 120 \\
\hline Effert et al. (1964) & & $80-200$ & 125 \\
\hline Segal et al. (1966) & 50 & $70-150$ & \\
\hline Edler (1967) & 53 & $90-190$ & 140 \\
\hline Winters et al. (1967) & 75 & $65-210$ & \\
\hline $\begin{array}{l}\text { Wharton and Lopez Bescos (1970) } \\
\text { Gramiak and Shah (197I) }\end{array}$ & 12 & $\begin{array}{l}80-150 \\
80-150\end{array}$ & 123 \\
\hline Pridie, Benham, and Oakley (197I) & & $70-120$ & \\
\hline Ross (1972) & 39 & $70-160$ & II4 \\
\hline Ziady et al. (1973) & 46 & $120-200$ & \\
\hline Layton et al. (1973) & 5 & $58-139$ & 92 \\
\hline
\end{tabular}

\section{Subjects and methods}

Forty-five normal subjects and one with lone atrial fibrillation were studied. Their ages ranged from 15 to 50 (mean 29) years and 32 were female.

The mitral anterior cusp echogram was recorded with the subjects supine and care was taken to record the maximum amplitude of mitral movement.

The apparatus used was an Eskoline 20 ultrasonoscope (Smith Kline Instruments) with an unfocused transducer. In 45 subjects, records were made directly from the oscilloscope with a Polaroid camera. In the latter part of the study an ultraviolet strip chart recorder (Honeywell Visicorder) was available and with it records were made in 5 subjects at chart speeds of 10 and $20 \mathrm{~mm} / \mathrm{s}$ and in 3 subjects at speeds from 10 to $100 \mathrm{~mm} / \mathrm{s}$. On the Polaroid records vertical markers indicating I $\mathrm{cm}$ of tissue depth were recorded at intervals of $0.5 \mathrm{~s}$, and on the strip chart records $0.2 \mathrm{~cm}$ depth markers were recorded at intervals of $2 \mathrm{~s}$.

On strip chart tracings recorded in 5 subjects at constant speed, the diastolic closure rate was measured from mitral echograms in which the form of the diastolic closure slope varied. In a further 3 subjects the diastolic closure rate was measured at varying chart speeds. Selection criteria which allowed reproducible measurement of the closure rate were established. Using only complexes which fulfilled these criteria, within-subject variation was assessed from strip chart recordings in two normal subjects and one with lone atrial fibrillation, while between-subject variation was investigated from the Polaroid records of $\mathbf{4 5}$ normal subjects.

\section{Results}

Variation in diastolic closure slope and measured diastolic closure rate

The echograms in Fig. I were recorded from the same subject at a single examination. The amplitude, the form of the diastolic closure slope, and the diastolic closure rate measured from the slope vary.
In record 4 (Fig. I), the amplitude is maximal and diastolic closure is essentially monophasic, i.e. has a single main component. In records I to 3 (Fig. I), the amplitude of all complexes is submaximal and diastolic closure is basically biphasic, i.e. has two main components, the first of which is relatively slow. The duration and speed of each of the two components vary: for the second component, this is well illustrated in record 3 (Fig. I).

Fig. 2, recorded from another subject, also illustrates the variability of the diastolic closure rate measured from complexes in which the form of the diastolic closure slope differs. In complexes 1,2 , and 8 the closure slope approximates closely to a monophasic form and the measured diastolic closure rates are in good agreement.

\section{Standard method of measurement of diastolic closure rate}

From Fig. I and 2 it can be seen that because an average slope can be determined with acceptable accuracy, measurement of the diastolic closure rate from a closure movement with a single component is technically easy and provides reproducible results. It is evident that when there is more than one main component, a decision on which of these to measure must be made. If, for a biphasic closure movement, the initial component is chosen, the measured diastolic closure rate is slow, and if the second component is measured, the diastolic closure rate is fast. Further, as is illustrated in Fig. I record 3, though measurement of the fast component of a biphasic closure movement may often produce a diastolic closure rate comparable to that measured from a monophasic one, more variation can occur. In our experience, a diastolic closure movement which may for the purposes of measurement be 

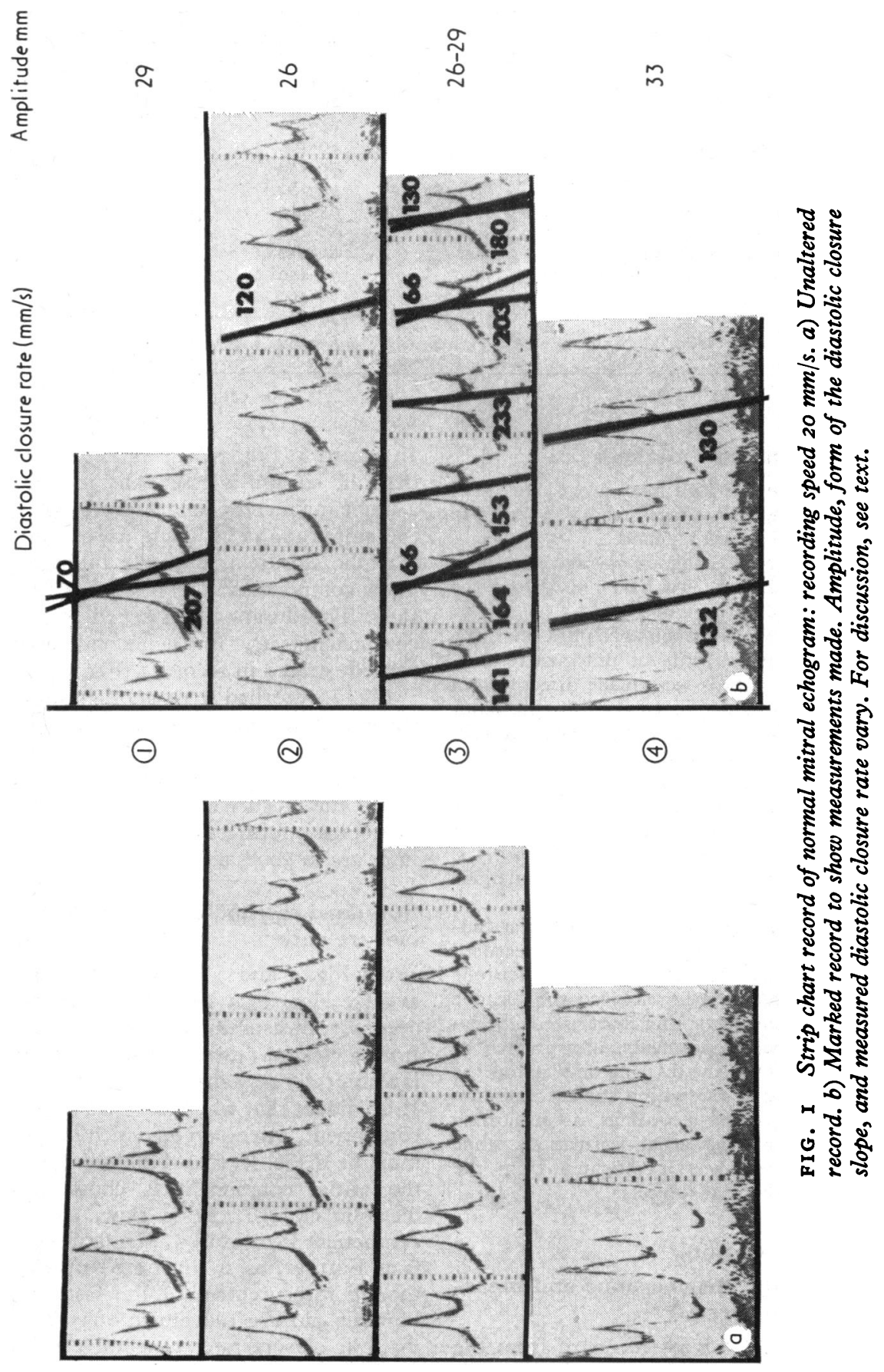

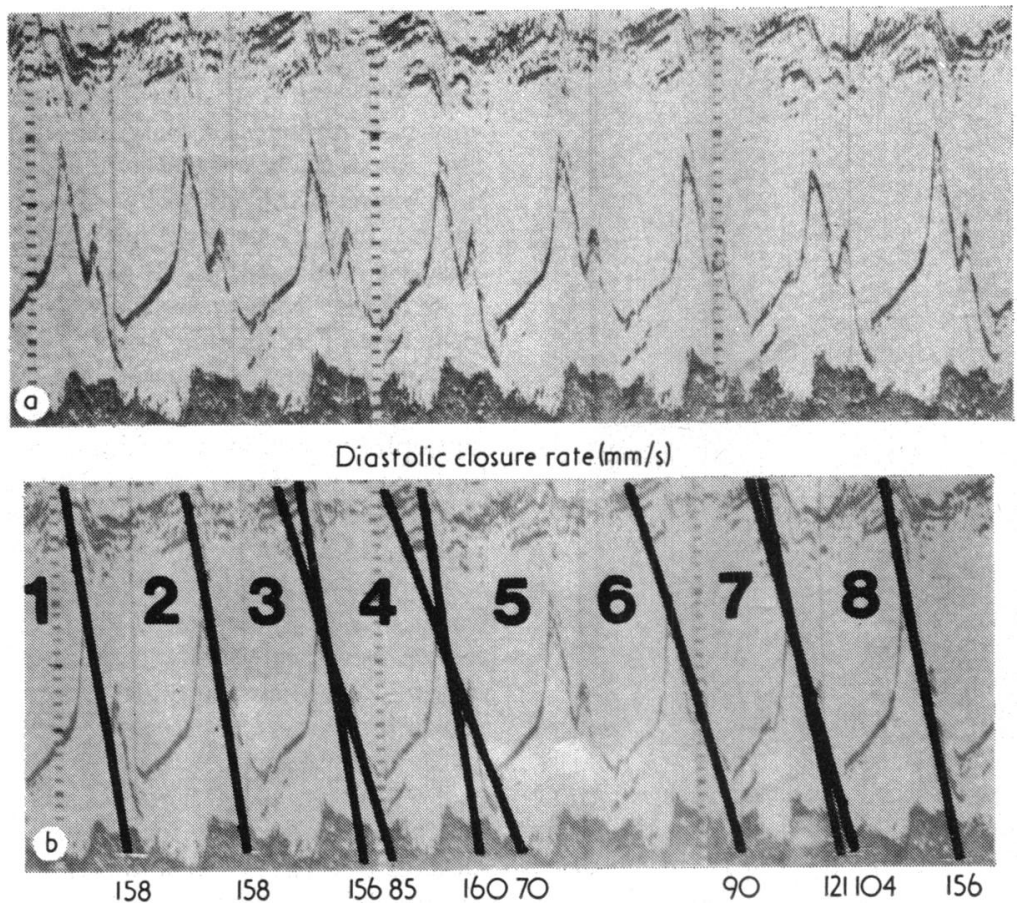

FIG. 2 Normal mitral echogram: recording speed $20 \mathrm{~mm} / \mathrm{s}$. a) Unaltered record. b) Marked record to show measurements made. Diastolic closure is essentially monophasic in complexes $I, 2$, and 8 and clearly biphasic in 3, 4, 6, and 7. For discussion, see text.

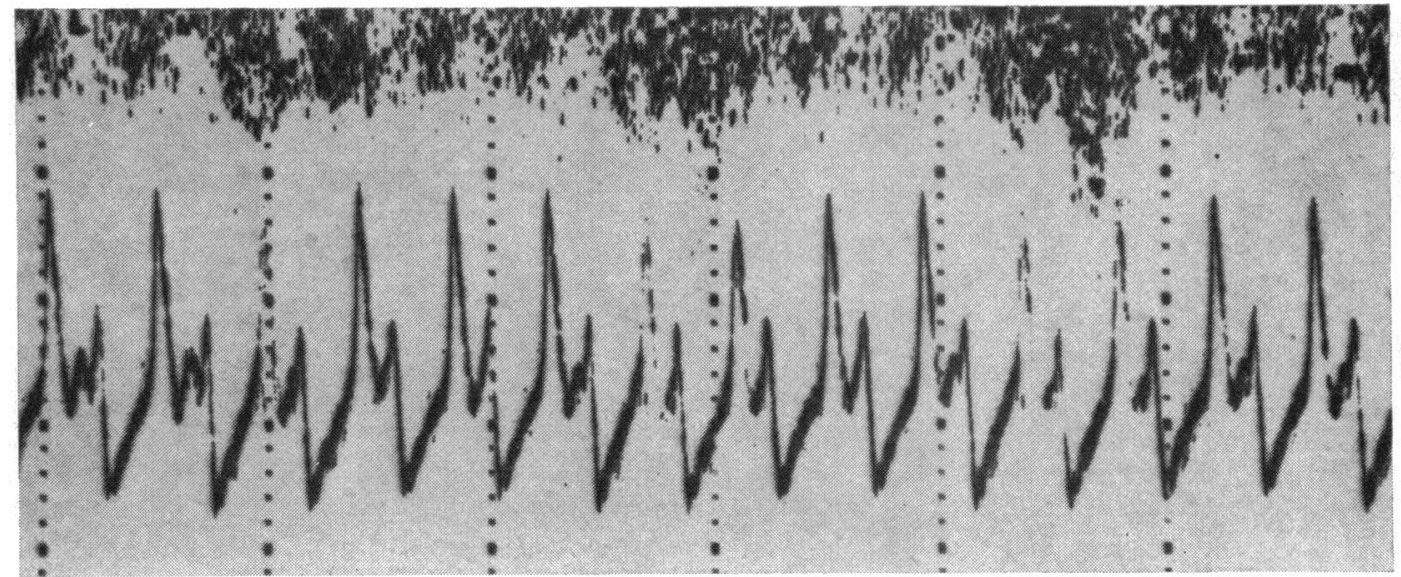

FIG. 3 Normal mitral echogram: recording speed $20 \mathrm{~mm} / \mathrm{s}$. Diastolic closure approximates closely to a monophasic form. For the purposes of measurement it can be regarded as monophasic: it is then technically easy to measure an average closure slope. 

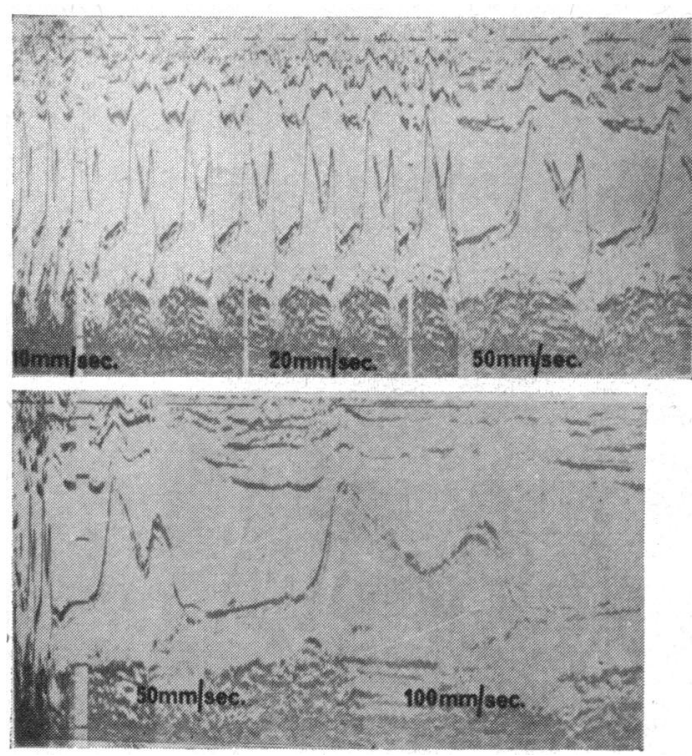

FIG. 4 Normal mitral echogram. At each recording speed it is possible to select complexes in which diastolic closure can be regarded as essentially monophasic. Because an average slope can be determined, these complexes are suitable for the measurement of the diastolic closure rate. regarded as monophasic can always be recorded from a normal mitral valve (Fig. I-6).

In Fig. I and 2, diastolic closure is monophasic only in complexes of maximal amplitude. We have, therefore, concluded that when echogram amplitude is maximal, the diastolic closure movement recorded from a normal mitral valve approximates closely to a monophasic form.

A further study was carried out to investigate the influence of recording speed on the form of the diastolic closure movement and in particular to determine whether movements which appear to be monophasic at low recording speeds are resolved into two or more components at high speeds. Echograms were recorded in 3 subjects at chart speeds from to to $100 \mathrm{~mm} / \mathrm{s}$ (Fig. 4-6). When echogram amplitude was maximal and chart speed was I0, 20 , or $50 \mathrm{~mm} / \mathrm{s}$, diastolic closure was recorded as a single major deflection (Fig. 4-6). With maximal echogram amplitude and a chart speed of $100 \mathrm{~mm} / \mathrm{s}$, some closure movements clearly approximated to a monophasic form (Fig. 5) but when, as in Fig. 6 multiple parallel echoes were recorded during diastolic closure, the form of the movement was difficult to identify. In so far as it was possible to be certain about the shape of these closure movements, it appeared to be intermediate between a definitely monophasic and a definitely biphasic form (Fig. 6). The significance of this finding is not clear: it may simply represent a slight change in angulation of the probe. It should, however, be noted that provided echogram amplitude was maximal, diastolic closure recorded at $100 \mathrm{~mm} / \mathrm{s}$ did not show the

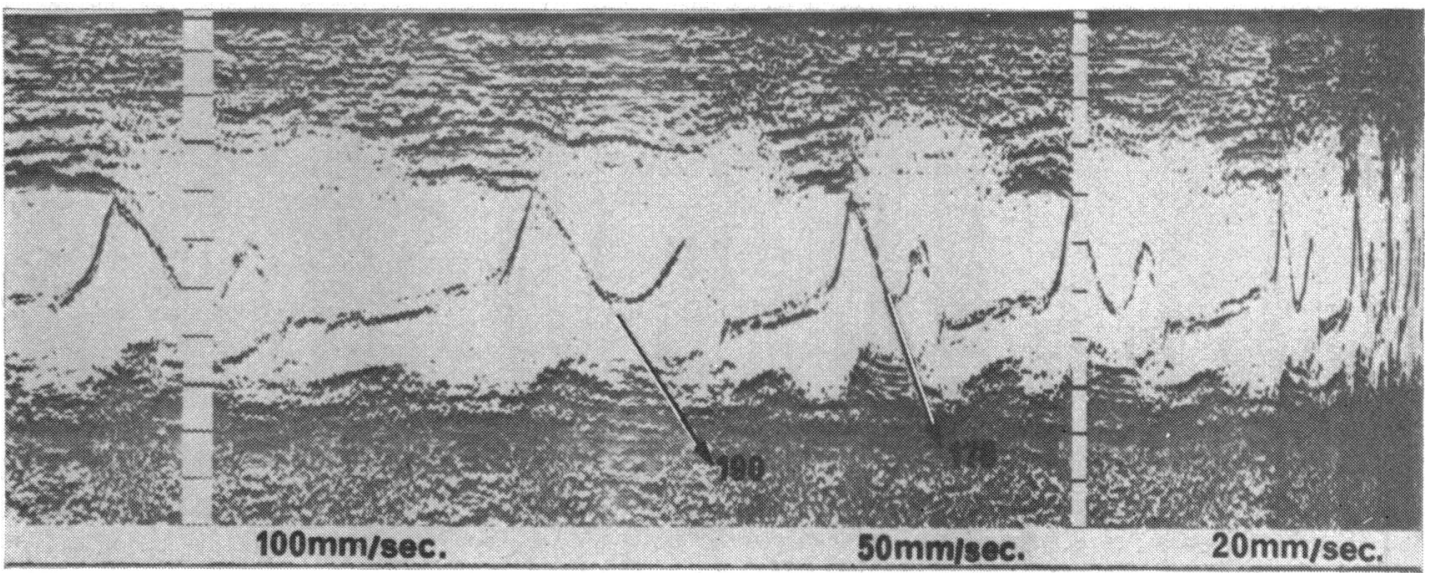

FIG. 5 Normal mitral echogram. When complexes in which the closure movement is essentially monophasic are selected, the measured diastolic closure rate does not alter significantly with chart speed. 


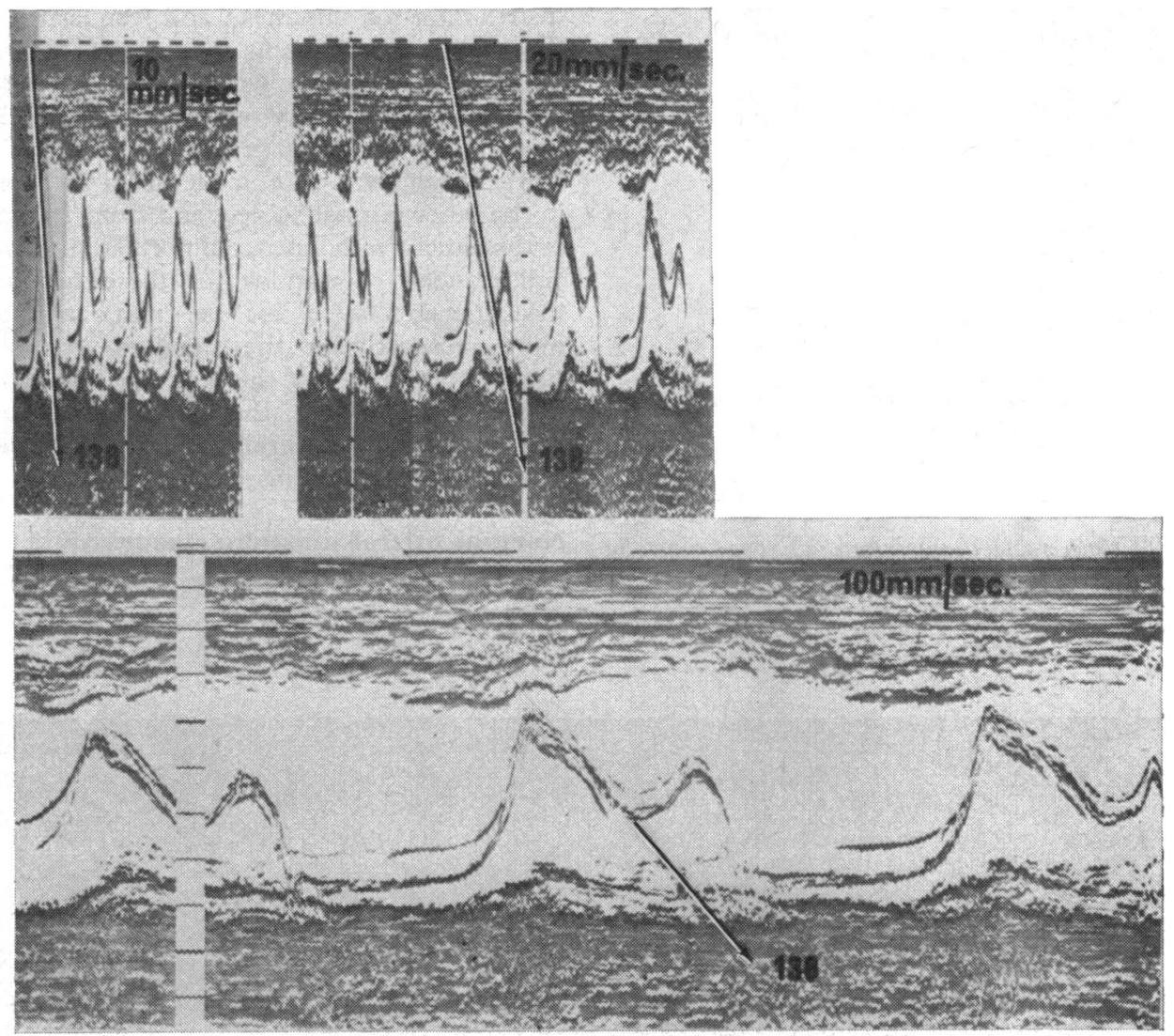

FIG. 6 Normal mitral echogram. At $100 \mathrm{~mm} / \mathrm{s}$ diastolic closure is intermediate between the essentially monophasic and clearly biphasic form seen in Fig. I and 2. For this reason and because multiple parallel echoes have been recorded in diastole, it is difficult to measure an average closure slope at $100 \mathrm{~mm} / \mathrm{s}$ chart speed.

major departures from the monophasic form seen in the low amplitude complexes in Fig. I and 2.

In those instances where essentially monophasic complexes were recorded at $100 \mathrm{~mm} / \mathrm{s}$, the measured diastolic closure rates were in accord with those determined from low speed records (Fig. 5). When traces of the type shown in Fig. 6 were recorded at $100 \mathrm{~mm} / \mathrm{s}$, it was difficult to measure an average slope but closure rates consistent with those calculated from low speed records could be obtained.

We suggest that to standardize results, measurement of the diastolic closure rate of the normal mitral valve should be made only on echograms in which the closure slope closely approximates to a monophasic form. We have found that measurement of the closure slope is more difficult on records taken at $100 \mathrm{~mm} / \mathrm{s}$ and we recommend that the diastolic closure rate be measured on complexes recorded at 20 or $50 \mathrm{~mm} / \mathrm{s}$.

\section{Within-subject variation of diastolic closure rate}

To investigate within-subject variation of the diastolic closure rate, only echograms in which the closure movement approximated closely to a monophasic form were selected for measurement. The diastolic closure rates of a series of complexes were measured on strip chart records from each of 3 subjects: 2 normals and I with lone atrial fibrillation.

Forty-five complexes were measured in I subject and the distribution of the closure rates obtained is shown in Fig. 7. The range is 130 to $210 \mathrm{~mm} / \mathrm{s}$, the mean $160 \mathrm{~mm} / \mathrm{s}$, and the standard deviation I4 $\mathrm{mm} / \mathrm{s}$. The curve superimposed is the normal 


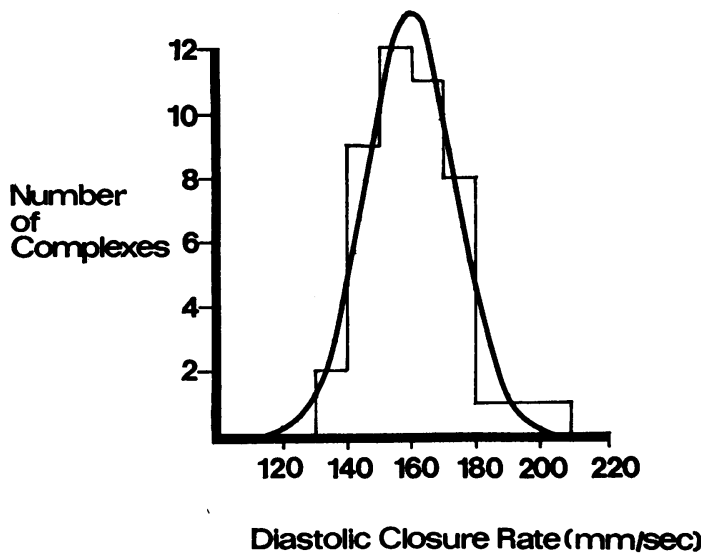

FIG. 7 Within-subject variation of the diastolic closure rate of the normal mitral valve. distribution for this mean and standard deviation. The data are a good fit to a normal distribution. This suggests that the within-subject variations are random and that no systematic bias has been introduced by the selection criteria.

Measurements were made from Is complexes in the other normal subject and from 13 complexes in the patient with lone atrial fibrillation. The means and standard deviations for these two series of measurements were $201 \pm I I \mathrm{~mm} / \mathrm{s}$ and $200 \pm 10$ $\mathrm{mm} / \mathrm{s}$, respectively: the standard deviations are comparable to that of the series in Fig. 7. In atrial fibrillation, therefore, the varying ventricular rate does not affect the mitral diastolic closure rate: this can be confirmed by inspection of Fig. 8.

\section{Normal mitral diastolic closure rate}

To investigate between-subject variation only echo-
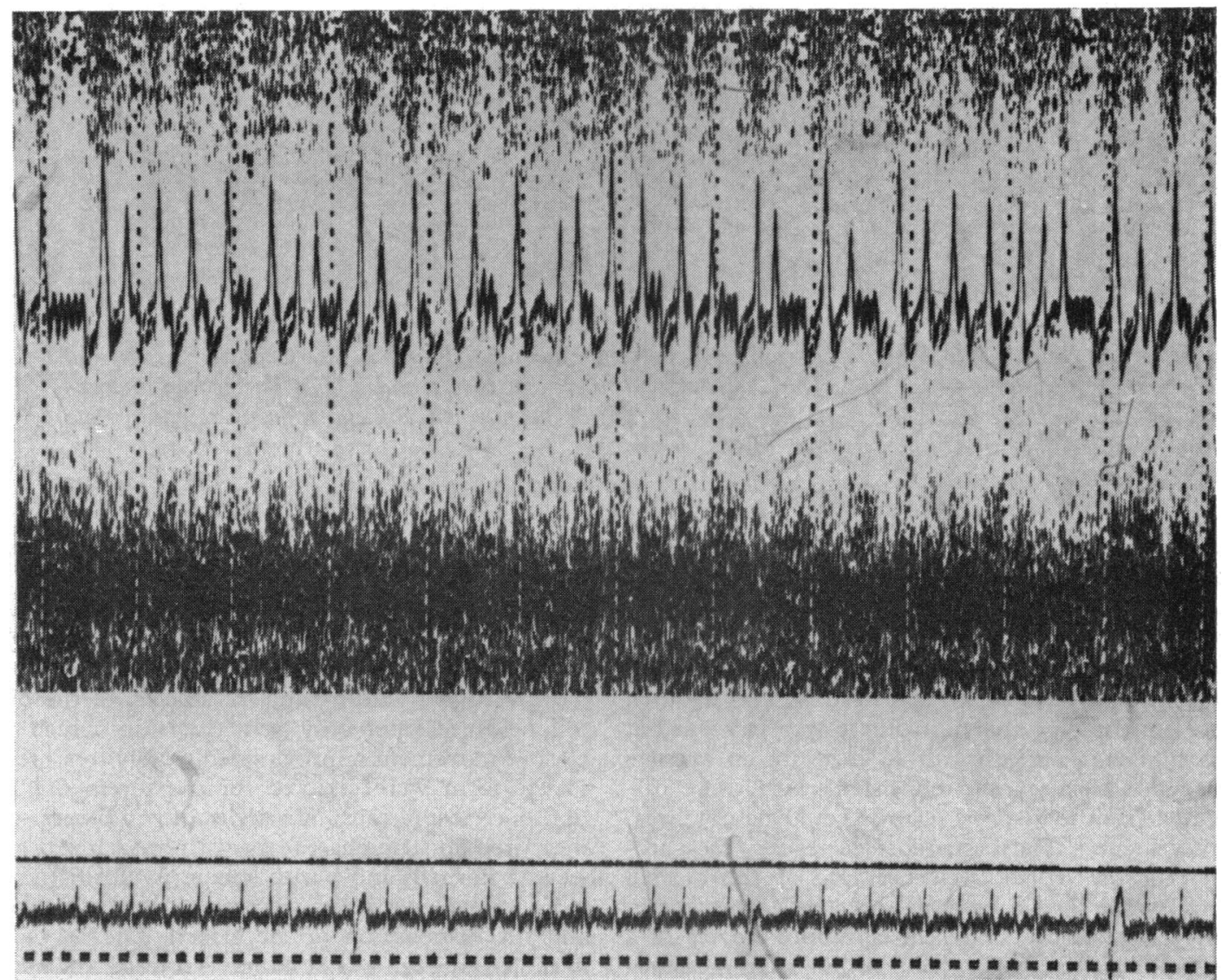

FIG. 8 Mitral echogram in lone atrial fibrillation: recording speed $10 \mathrm{~mm} / \mathrm{s}$. 
grams in which the diastolic closure movement approximated closely to a monophasic form were selected and the diastolic closure rate was measured from the Polaroid records of 45 normal subjects. At least 2, and up to 6, complexes were measured in all subjects and a mean diastolic closure rate was calculated for each. The standard deviations were comparable to those obtained from the 3 subjects in whom a larger series of measurements was made. The mean values for the 45 subjects are shown in Fig. 9. The range is 128 to $234 \mathrm{~mm} / \mathrm{s}$, with a mean of $176 \mathrm{~mm} / \mathrm{s}$ and a standard deviation of $29 \mathrm{~mm} / \mathrm{s}$. When these results are compared with those obtained from multiple measurements in a single subject (Fig. 7), it is evident that the ranges are comparable. However, the values from the group of 45 subjects are more evenly distributed throughout the range and give a standard deviation of more than twice that of the within-subject study. The findings suggest that there is a real between-subject variation in the normal mitral diastolic closure rate.

\section{Discussion}

The variation in published values for the diastolic closure rate of the normal mitral valve (Table I) undoubtedly reflects differences in methods of recording: some of the workers used Polaroid records of the oscilloscope display, and others, employing an analogue gate system, recorded a single echo on an ink or photographic recorder. Both these recording methods have disadvantages (Ross, 1972; Joyner, 1972) and echograms obtained by them are unlikely to be technically comparable.

The variation in published normal values may also reflect differences in methods of measurement: few of the authors detail their method of measurement, none comments on the variable form of the recorded diastolic closure movements, and only one indicates the extent of the variation in calculated diastolic closure rates from a single subject. In echograms in which the closure movement has two components, Ross (1972) measures the slower first component. Other authors illustrate diagrammatically the method of measurement when closure is monophasic but fail to describe how the diastolic closure rate was calculated from their actual records which are often biphasic.

Strip chart records are a major advance. Because multiple echoes and an unlimited number of cardiac cycles can be recorded, the accuracy of measurements made from the echograms can be improved. From strip chart records we have concluded first that essentially monophasic diastolic closure movements can always be recorded from a normal mitral valve, and secondly that when diastolic closure approximates closely to a monophasic form the amplitude of the echogram is maximal, while when closure is clearly biphasic the amplitude is submaximal. The form of the recorded closure movement is thus a function of the amplitude of the echogram.

We have suggested that to standardize measurement of the diastolic closure rate, only complexes in which diastolic closure approximates closely to a monophasic form should be selected for measurement and we have observed that these echograms are of maximal amplitude. The echogram amplitudes for the 45 subjects whose mitral diastolic closure rates are charted in Fig. 9 ranged from 22 to $4 \mathrm{I} \mathrm{mm}$ (mean $29 \pm 4.3 \mathrm{~mm}$ ). These are higher values than most of those previously reported (Segal et al., 1966; Winters et al., 1967; Edler, 1967; Wharton and Lopez Bescos, 1970; Ross, 1972) and may indicate that other workers have not always recorded the maximal echogram amplitude. Wild and Pridie (1972) did not consider the diastolic closure slope or diastolic closure rate but stated that for a reproducible mitral echogram the amplitude should be maximal. Selection of suitable complexes for measurement according to the form of the diastolic closure movement has the practical advantage that they can be identified on previously recorded traces. It is otherwise impossible to decide which echograms on such traces are of maximal amplitude.

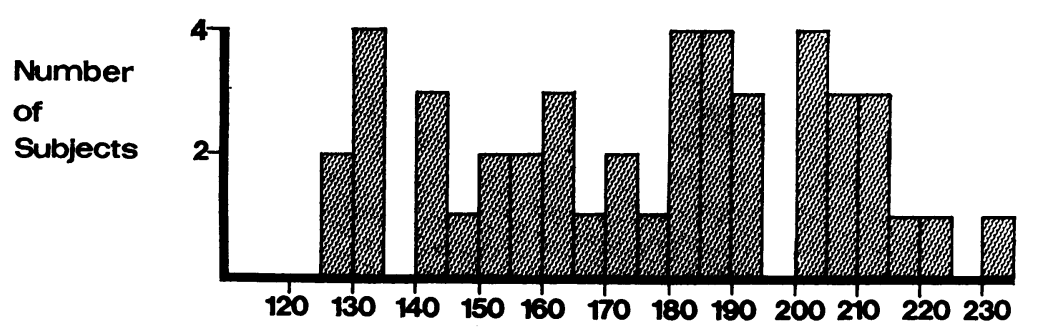

Diastolic Closure Rate ( $\mathrm{mm} / \mathrm{sec})$

FIG. 9 Between-subject variation of the diastolic closure rate of the normal mitral valve. 


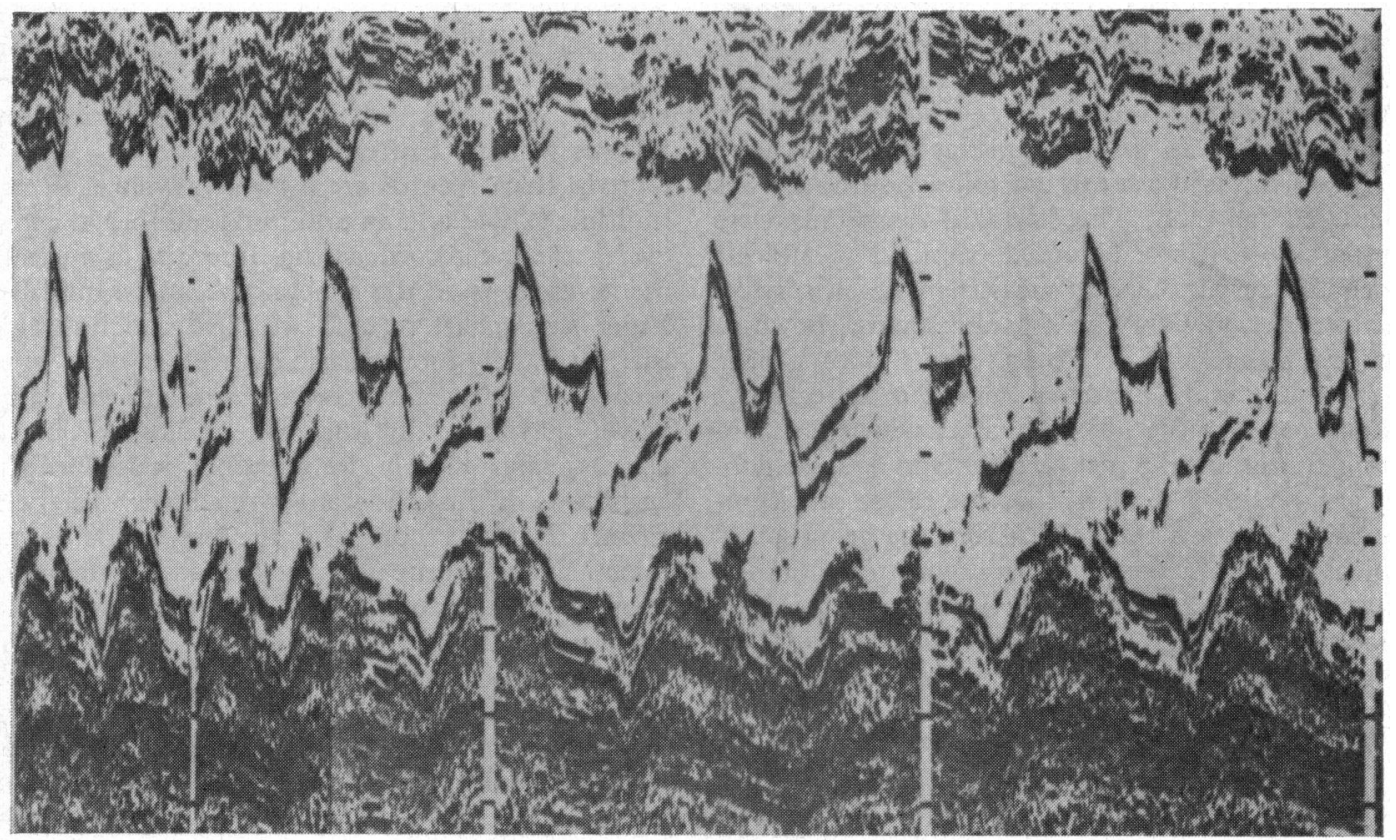

FIG. IO Mitral echogram from a patient with systemic hypertension: chart speeds Io and 20 $\mathrm{mm} / \mathrm{s}$. Essentially monophasic diastolic closure movements are recorded anterior to biphasic ones.

Our finding that the form of the recorded diastolic closure movement varies with echogram amplitude may reflect differing patterns of diastolic closure at different parts of the mitral anterior cusp. Echograms of maximal amplitude can theoretically be expected to originate from the free margin of the leaflet, and echogram amplitude diminishes progressively as the ultrasonic beam is directed away from the region of the free edge towards the root of the cusp. Therefore, our observations may indicate that during diastole, the free margin of the leaflet closes in a single, essentially uninterrupted movement while portions of the leaflet closer to the root close in two distinct 'movements. In Fig. ro several echograms comprise both essentially monophasic and essentially biphasic closure movements: the origin of the monophasic movement is always anterior to that of the biphasic one, consistent with its derivation from the free edge of the leaflet. Fig. Io illustrates how, particularly when using an analogue gate system, the most anterior portion of the echogram may be omitted. In these circumstances a biphasic closure movement originating behind the free margin of the cusp will be recorded.

Recording speed has a bearing on the accuracy with which the diastolic closure rate can be measured. We have discussed the difficulties which can arise in measuring closure movements recorded at I00 mm/s (Fig. 4-6). It should, however, be stressed that though it is easier to draw an average slope at low speeds, another source of error will become important at very low speeds. Thus, the slope is calculated from the ratio of a length measured along the position axis to a length measured along the time axis: at low speeds, the relative error in measuring the latter will increase and an increased error in the calculated diastolic closure rate will result. We recommend that as a suitable compromise between these two possible sources of error, the diastolic closure rate should be measured on essentially monophasic complexes recorded at 20 or $50 \mathrm{~mm} / \mathrm{s}$.

Applying our standard method of measurement we have recorded higher mitral diastolic closure rates in normal subjects than most of those previously published. Layton et al. (1973) used an analogue gate system and attributed the slow closure rates which they observed to the fact that they were recording at speeds of $100 \mathrm{~mm} / \mathrm{s}$. We have made records in normal subjects at chart speeds up to $100 \mathrm{~mm} / \mathrm{s}$. We have no evidence that the measured diastolic closure rate decreases as the chart speed increases. We have, however, found that measurement of the mitral diastolic closure rate may on occasion be difficult at $100 \mathrm{~mm} / \mathrm{s}$. 
Though we may have been able to make reproducible measurements of the diastolic closure rate and have shown that the standard deviation of within-subject measurements is acceptably small, it is still possible to record widely varying closure rates from a single subject (Fig. 7). To estimate the diastolic closure rate accurately it is thus essential to make measurements from a series of complexes. Because of the disadvantages of other recording methods, these measurements are best made on strip chart records. Measurement of monophasic closure movements on strip chart records should provide results of sufficient accuracy to allow investigation of the recent suggestion that the mitral diastolic closure rate can be used as an index of left ventricular filling (Layton et al., 1973).

\section{References}

Edler, I. (I96I). Atrioventricular valve motility in the living human heart recorded by ultrasound. Acta Medica Scandinavica, 170, Suppl. 370, 83.

Edler, I. (I967). Ultrasound cardiography. Ultrasonics, 5, 72.

Effert, S., Bleifeld, W., Deupmann, F. J., and Karitsiotis, J. (1964). Diagnostic value of ultrasonic cardiography. British fournal of Radiology, 37, 920.

Gramiak, R., and Shah, P. M. (I97I). Cardiac ultrasonography. A review of current applications. Radiologic Clinics of North America, 9, 469.

Joyner, C. R. (1972). Echocardiography. Circulation, 46, 835.

Joyner, C. R., Reid, J. M., and Bond, J. P. (1963). Reflected ultrasound in the assessment of mitral valve disease. Circulation, 27, 503.

Layton, C., Gent, G., Pridie, R., McDonald, A., and Brigden, W. (1973). Diastolic closure rate of normal mitral valve. British Heart fournal, 35, 1066.

Millward, D. K., McLaurin, L. P., and Craige, E. (1973).
Echocardiographic studies of the mitral valve in patients with congestive cardiomyopathy and mitral regurgitation. American Heart fournal, 85, 413.

Pridie, R. B., Benham, R., and Oakley, C. M. (197I). Echocardiography of the mitral valve in aortic valve disease. British Heart fournal, 33, 296.

Ross, F. G. M. (1972). Ultrasonic investigation of the heart. In Ultrasonics in Clinical Diagnosis, p. I20. Ed. by P. N. T. Wells, Churchill Livingstone, Edinburgh and London.

Segal, B. L., Likoff, W., and Kingsley, B. (1966). Echocardiography. Clinical application in mitral stenosis. fournal of the American Medical Association, 195, 161.

Segal, B. L., Likoff, W., and Kingsley, B. (1967). Echocardiography. Clinical application in mitral regurgitation. American fournal of Cardiology, 19, 50.

Sweatman, T., Selzer, A., Kamagaki, M., and Cohn, K. (1972). Echocardiographic diagnosis of mitral regurgitation due to ruptured chordae tendineae. Circulation, 46, 580.

Tallury, V. K., DePasquale, N. P., and Burch, G. E. (1972). The echocardiogram in papillary muscle dysfunction. American Heart fournal, 83, 12.

Wharton, C. F. P., and Lopez Becos, L. (1970). Mitral valve movement: a study using an ultrasound technique. British Heart fournal, 32, 344.

Wild, J., and Pridie, R. B. (I972). The requirements of a normal mitral echogram (abstract). Physics in Medicine and Biology, 17, 437 .

Winters, W. L., Riccetto, A., Gimenez, J., McDonough, M., and Soulen, R. (1967). Reflected ultrasound as a diagnostic instrument in study of mitral valve disease. British Heart fournal, 29, 788.

Ziady, G., Madeira, H., Pridie, R., Callen, G., and Oakley, C. (1973). Diastolic closure rate of mitral valve as determined by ultrasound. In Proceedings of the British Cardiac Society. British Heart fournal, 35, 560.

Requests for reprints to Dr. J. Christine Rodger, Division of General Medicine Unit B, Stobhill General Hospital, Glasgow G2I 3UW. 